\title{
BALANCE OF SUPPLY AND DEMAND OF THE CEREALAND INFLUENCING FACTORS IN CHINA: FROM THE PERSPECTIVE OF THE COST
}

\author{
Bingqiang Li \\ Bingqiang Li \\ School of Entrepreneurship, Lishui University, \\ Zhejiang Lishui, P.R.C \\ AndyLBQ@163.com \\ Article info \\ Paper category: Original scientific paper \\ Received: 10. 4. 2017. \\ Accepted: 20.9.2017. \\ JEL classification: Q०1, Q18, Q21
}




\begin{abstract}
The balanced supply and demand of the cereal is essential for achieving economic sustainable development in China. The wheat and products, the rice (including the milled equivalent), and the maize and products are three main cereals in China, the three cereals but the rice (including the milled equivalent) in China were generally seriously comparatively insufficient before 1997, and then became fully sufficient. The co-integrative test demonstrated that there existed long-term equilibrium between balance of supply and demand and influencing factors, and the correcting coefficient was about 2.2 percent. As for balance degree of supply and demand, increase of machinery cost, daily-average labor price and indirect cost would improve it, increase of fertilizer expenditure and labor-input quantity would deteriorate it at short-term. The Granger causality test implied that balance of supply and demand owned interactive effect with laborer-input quantity, but not with the other cost. The highlight of this article was evaluating hypothesis of "Who will feed China" and influencing factors from perspective of the cost, achieving that the above hypothesis was not a real problem in China.
\end{abstract}

\title{
KEYWORDS:
}

Supply-demand balance; Cereal; Food safety; Co-integrative analysis 


\section{THE QUESTION PROPOSED}

Since Brown (1995) published the book named "Who will feed China", declared that China's cereal shortage would induce global cereal crises, which made China's food problem be global focus. In fact, Yeh (1989) brought the problem of China Mainland's grain crises, but did not arise much attention until Brown's announcement. At the same time, Bruins and $\mathrm{Bu}$ (2006) attached importance of increase of the grain reserves to achieve China's food security, which explored the significance of maintaining balance of the food's supply and demand. With quantity of population being over 1.36 billion in 2015 , extensive production mode of agriculture, acceleration of the farmland disappeared for reason of implementation of rapid urbanization and industrialization and the red line of the cultivated land's quick destroy by current developing mode and development background, made the problem of cereal production be important composition of the China-threat theory. In fact, governments in China had implemented corresponding countermeasures actively to promote efficiency of agricultural production especially that of the cereal, so as to avoid the problem of national safety induced by large quantity importing of the cereal. Therefore, the problem of grain safety is that of balance of supply and demand of the cereal to some extent.

The grain and the cereal were the same to some extent. At present, China's food security had raised global attention (Liu, Pieniak, Verbeke, 2014; Holtkamp, Liu, Mcguire, 2014; Liu 2014; Wei, Zhang, Shi et. al., 2015; Chen, Nie, 2016), and the consumer was anxious for food grain safety in China (Zhu, Jackson, Wang, 2016). Fan, Lal, Cao, et.al., (2013) considered that strategy combining engineering-based measures with biological-approaches of inherent soil productivity improvement could improve production of the cereal in China, which might induce agricultural miracle in China (Bramall, 2008). Wang, Wu, Zhao, et. al., (2011) analyzed the problem of grain quality safety in China, and brought some countermeasures to solve it.

There were many factors influencing cereal safety in China, and many scholars made relevant studies on this. Fang (1994) considered that price fluctuation made China's grain production be in state of crises. Fan, Stewart, Payne, et.al., $(2005)$ considered that increasing water-holding capacity was helpful to achieve grain yield decline and sustainable productivity. Pan, Smith, Pan, et. al., (2009) regarded the role of soil organic matter as an important factor for achieving efficient productivity and yield stability of the cereal. Wang, Zhang, Cai, et. al., (2009) considered that improvement of agricultural infrastructure, greater use of science and technology, increased fiscal input, protection of relevant resources, adaptation of climatic change, support for the farmers' livelihood, improvements in grassland agriculture, and controls on population growth were important factors for achieving promotion of the cereal's production. Xiong, Conway, Lin, et.al., (2009) con- 
sidered that the climate change, the water availability and the socio-economic scenario were main factors influencing cereal production. Zhang and Huang (2012) found that inter-annual variations in precipitation and solar radiation were drivers for cereal yield (including the rice, the wheat and the maize). Wang, Wu, Zhao. et.al., (2014) thought that virtual water flow related to the grain resulted in negative impact on relevant development and induced to serious threat to food security. In addition, some researchers made relevant explanation on China's grain safety from many perspectives, such as global economy (Zhou, Xin, 2006), optimization (Shea, 2010), cultivated land (Zhang, 2013), economic ecologization (Li, Zhang, 2016), macro economy (Xu, Lu, Wang, 2016).

From the above research, it can be seen that many studies cared about the cereal's safety and its influencing factors in China, but scare studies caring about the cost influencing on balance of supply and demand of the cereal were brought, and this was the cut point of this article. In fact, the problem of the cereal's safety mainly caused by comparative large quantity of importing, so there was necessary to promote relevant domestic production, and this was much relevance to corresponding costs, which implied that various costs would influence the cereal's safety significantly, and this was essential for achieving balance of supply and demand of the cereal under condition of production being comparatively insufficient in China. This article analyzed degree of balance of supply and demand of the cereal in China, then made analysis on cost factors influencing degree of balance of supply and demand by taking co-integrative model, with highlight being evaluating hypothesis of "Who will feed China", and influencing factors from perspective of the cost.

\section{BALANCE OF SUPPLY AND DEMAND OF THE CEREAL}

Here, the cereal is used to represent the grain, for reason of FAOs' relevant regulation. According to FAOs, domestic utilization could be divided into food, food manufacturing (abbreviated as "food manu"), feed, seed, waste and other uses, and it can be learned that food occupied majority of domestic utilization, which was $62.40 \%, 63.23 \%, 60.49 \%, 55.62 \%$ and $46.12 \%$ in 1975, 1981, 1991, 2001 and 2011 respectively, indicating being food being very important for China's cereal consumption. The fact of the cereal being food mainly demonstrated that the hypothesis of "Who will feed China" was a fact to some extent. Meanwhile, balance of supply and demand was another problem, indicating self-supply level of one nation being more important, and this was what we cared about.

The cereal included many categories, and there was not necessary to make analysis on each category. In fact, three main cereals were the wheat and products, the rice (including the milled equivalent), the maize and products in China, e.g. sum of the above three occupied for the domestic utilization was about or over 90 
percent of the cereal. Here, China only referred to Mainland, and did not include Hong Kong, Taiwan and Macao. Therefore, we only cared about the above three categories as to the following analysis, and did not care about other categories of the cereal, e.g. the bean was not to be considered. At the same time, sum of ratios of the above three achieved steadily increasing trend from 1975 to 2011 , and that had reached over 90 percent since 1979. Seen from the three categories, ratio of the quantity of the rice (including the milled equivalent) occupying the domestic utilization of the cereal was about 40 percent in $1975^{-19}$ 89, then appeared significant decreasing trend, and then reduced to be within 3o percent. Ratio of the quantity of the wheat and products occupying the domestic utilization of the cereal was about 20-3o percent generally, demonstrated the trend of increasing firstly, then comparative stability, and then slight decreasing, which got 20 percent in 1977 and achieved maximum value in 1997. The changing trend of ratio of the quantity of the maize and products occupying the domestic utilization of the cereal was the opposite to that of the rice (including the milled equivalent), which implied increasing trend generally. E.g. that was over 30 percent since 1993 (except that in 1997), and was over 40 percent since 2009 .

Figure 1.: Ratios of the quantity of three main cereals occupying domestic utilization of the cereal in $1975^{-2011}$

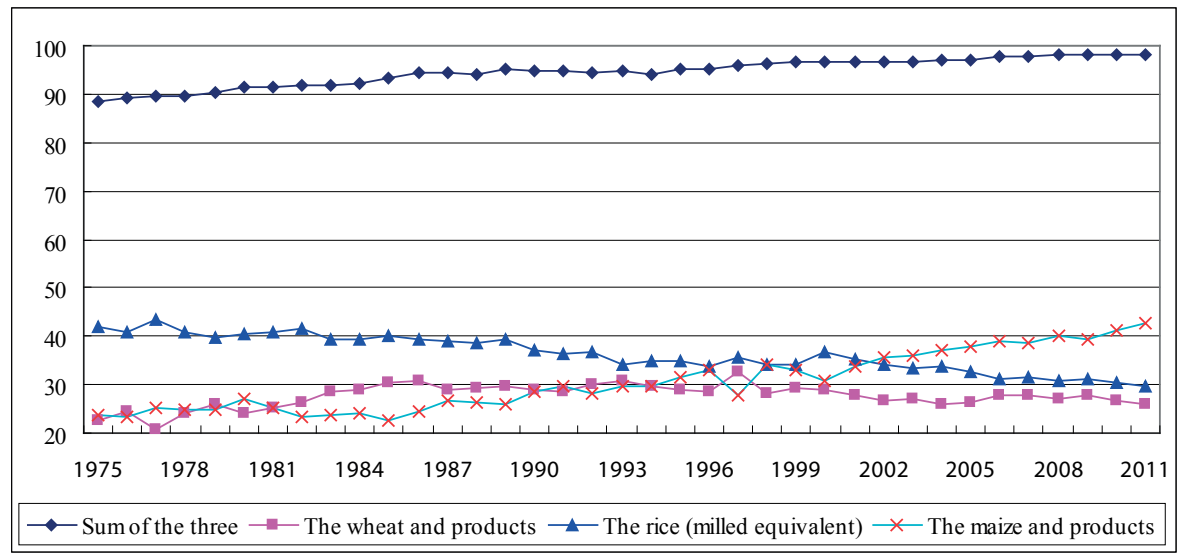

Source: Author's

As to China, the problem of balance of supply and demand of the cereal was inadequate supply (or, production) of the cereal to some extent. Therefore, importing might be a very important method to meet requirement of domestic utilization. The less importing was, the better degree of balance of supply and demand of the cereal would be. In this paper, took ratio of import quantity of one category of the cereal occupying its domestic utilization as index measuring degree of balance of supply and demand, and brought out the following judging criterion: if the 
ratio was over 10 percent, it was considered that balance of supply and demand was serious insufficient; if the ratio was over 5 percent and less than 10 percent, it was considered that balance of supply and demand was comparative insufficient; if the ratio was over 2.5 percent and less than 5 percent, it was considered that balance of supply and demand was basically sufficient; if the ratio was less than 2.5 percent, it was considered that balance of supply and demand was fully sufficient. The reason of the above criterion was that central government in China usually took ratio of import quantity of cereal occupying its domestic utilization being 5 percent as the basically measuring index, and that ratio being over 10 percent would induce adjustment of national macro policies to regulate domestic production of the cereal. Something should point out that the above judgment was based on status quo in China, and it might be unsuitable for degree of balance of supply and demand of the cereal in other nations. Put relevant data into the calculating method, degrees of balance of supply and demand of the cereal were achieved, and Figure 2. demonstrated it.

Seen from degree of balance of supply and demand of the cereal (excluding beer), it can be learned that was over 2.5 percent generally before 1997, and this was the period of Brown's bringing out judgment of the cereal's self-sufficient safety in China. Later, China accelerated support of production of the cereal, and made the average ratio be within 2.5 percent, which implied to be stage of full sufficient. But, as per different categories of the cereal, there existed much obvious difference. E.g. degree of balance of supply and demand of the rice (including the milled equivalent) was almost zero in 1975-2011, which implied China's demand of the rice (including the milled equivalent) was basically supported by domestic production. Degree of balance of supply and demand of the maize and products was basically within 5 percent, and appeared certain fluctuation before 2005 , then that was in stage of fully sufficient after that period. Meanwhile, degree of balance of supply and demand of the maize and products was over 20 percent in 1994, which was an obvious disturb value, and this might be the reason of Mainland's implementing deepening open and reform policy in 1992 and its influence on the maize owning certain time lag effect. Degree of balance of supply and demand of the wheat and products was comparatively larger than those of the other two categories, e.g. the ratio in 1977-1984, 1987-1992 and $1995^{-19}$ was about or over 10 percent respectively, that in $1975^{-1997}$ was over 5 percent respectively (except that in 1976), and that in 2004, was an obvious disturb value, then that was less than 2.5 percent after 2004 respectively. Therefore, it can be considered that the wheat and products' degree of balance of supply and demand owned transformation from stage of serious insufficient to stage of fully sufficient. 
Figure 2.: Self-sufficient ratios of main categories in $1975^{-2011}$

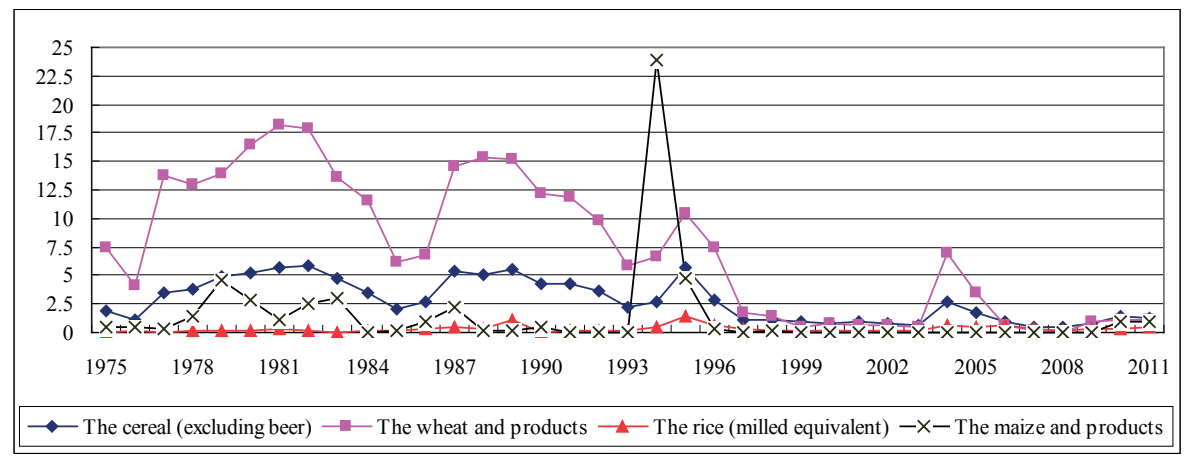

Source: Author's

Now, we turned to make analysis on the degree of balance of supply and demand from aspect of net import, and the detailed result was demonstrated in Figure 3. with unit being million metric tons. Seen from the cereal (excluding beer), it can be learned that net import was positive generally in 1975-1996, and that achieved about 20 million metric tons in 1995, while this was the time of Brown's bringing out relevant judgment. After that, net import quantity appeared decreasing trend significantly, and owned negative trend generally in 1997-2009 (except that in 2004), and that achieved -20 million metric tons in 2003, then appeared increasing trend after 2010. Seen from the wheat and products, the changing trend of net import was similar to that of the cereal (excluding beer), but its change was comparative smoother generally. Seen from the rice (including the milled equivalent), it can be learned that quantity of import was basically equal to quantity of export, and the quantity of import was slightly larger than the quantity of export, only net import in 1989, 1995 and 2003 was significant larger than zero respectively, but the gap was within 4 million metric tons generally, which indicated that maintained state of comparative equilibrium to some extent. Seen from the maize and products, there was net import in 1975-1983, 1994-1996, and net export in 1984-1993, 1997-2008 respectively, with characteristic of quantity of net export exceeding 16 million metric tons in 2003 and slightly net import after 2009. Comparison with the above, it can be learned that net import of the cereal (excluding beer) or the wheat and products vibrated much, while that of the rice (including the milled equivalent) and the maize and products changed slightly, but net import of the cereal (excluding beer) in 1995 and 2003 and the maize and products in 2003 changed much respectively, and this might be reason of acceleration of China's open economy in 1992 and time lag effect of entering WTO in 2001. 
Figure 3.: Net imports of main categories in 1975-2011

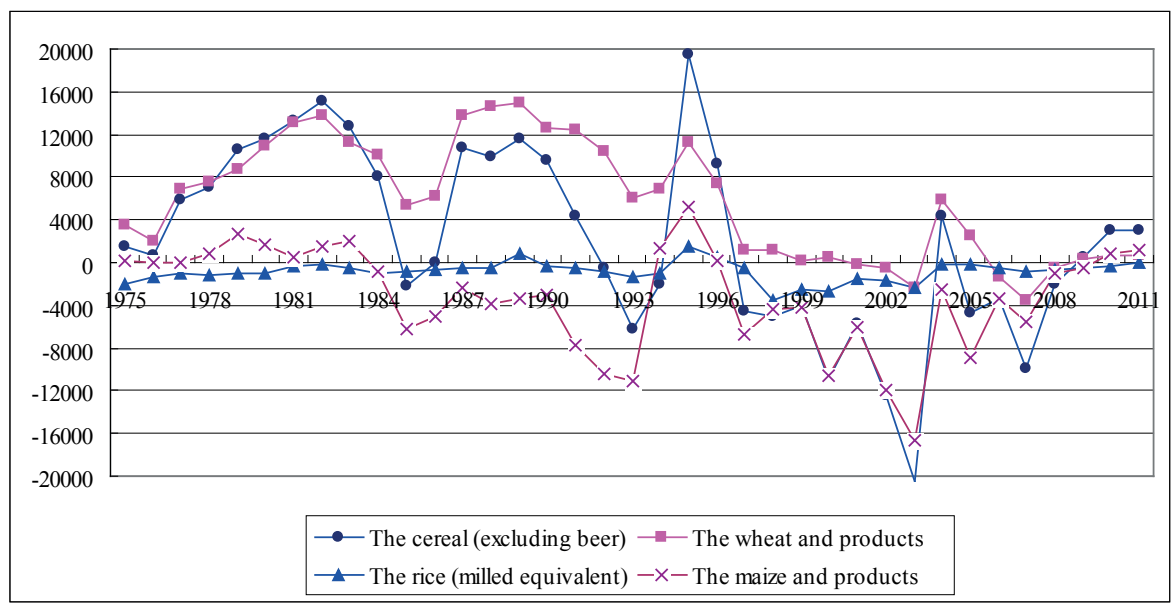

Source: Author's

From the above analysis, we could learn that balance of supply and demand of the cereal in China improved gradually, and the hypothesis being "Who will feed China" was not a real problem for China and the whole world, for reason of China could feed itself comparatively well. In other words, the rapid economic development and large quantity of population in China might not be a threat to stability of the world, on the contrary, which would induce driving force for the world, for reason of China's high economic growth rate being an important engine for economic recovery for many countries.

\section{EMPIRICAL ANALYSIS ON INFLUENCING FACTORS}

The balance of the cereal's supply and demand in China was influenced by many factors, such as the cost, the earning, the domestic environment, the international environment. As the above mentioned, we made relevant analysis from angle of the cost, for reason of the cost being most important aspect for China's achieving balance of supply and demand of the cereal. As time went on, the cost of the labor in China increased rapidly, and this might influence balance of supply and demand of the cereal sharply. China's price had changed much, which would affect the quantity of the physical cost, and this might influence balance of supply and demand of the cereal significantly. Therefore, the detection was made from aspects of the laborer's input and the physical cost to analyze influencing factors.

The laborer's input took variables of the quantity of labor input and the daily average labor price, with unit being each per mu and Yuan respectively, which were used to tell the quantity of labor and the level of labor wage's influence on balance of supply and demand of the cereal. The other costs input included aspects of the direct cost and 
the indirect cost. The direct cost can be detected from angles of the fertilizer expenditure and the machinery cost with unit being Yuan per mu respectively, with feature of influence of the fertilizer and agricultural modern degree respectively. The indirect cost included many items, such as the holder's assets discount, the purchase and repair expenditure of the small agricultural equipment, the management and other indirect cost, the sales expenditure, and combined the above items being one factor for reason of comparatively enormous statistical change of this kind of agricultural cost during 1975-2011 in China, with unit being Yuan. In addition, the index of cereal's supply and demand's balance was measured by percent of the quantity of import occupying the quantity of domestic utilization. For achieving more effective result, the above indexes were pooled data of the mentioned three main cereals. E.g. the index of balance degree of the cereal's supply and demand was got by the three main cereals' pooled quantity of import and pooled quantity of domestic utilization respectively. Here, mu is the official unit for measuring the land's acreage and majority of official statistics yearbook take it, with the equation of one mu being 6.07 acres. Therefore, for reason of being coincided with official statistical method in China, we took mu as unit of the land's acreage to make consequent analysis. Except the data got from www.fao.org, the other was available from www.npcs.gov.cn and Compilation of Chinese Agricultural Product Cost and Benefit in 2006 and 2012. In fact, we only could get relevant compiled data of the above three main cereals from official website of www.npcs.gov.cn.

The co-integrative analysis was implemented to detect influencing factors and their impacting directions on China's cereal's supply and demand's balance. It was necessary to make unit root test before making co-integrative analysis. Only variables with the same order of integration could be used to discuss whether there existed co-integrative relationship or not, and it would be no co-integrative relationship if there was not the same order of integration. The empirical analysis usually carried unit root test to judge the stability and the order of integration of the time series index, and test methods mainly included DF Test, ADF Test, PP Test, KPSS Test and NP Test. Here, GXB, HFF, JXF, JJF, LDL, LDW represent balance degree of the cereal's supply and demand, the fertilizer expenditure, the machinery cost, the indirect cost, the quantity of labor input, the daily average labor price respectively. For convenience of reducing influence of the time trend, logarithmic form of the above indexes was taking as variables used for the following analysis.

\subsection{Unit Root Test}

ADF test and Mackinnon critical value were used to make relevant judgment (see Table 1.). The result implied that each variable could not refuse unit root hypotheses under state of level, while refused unit root hypotheses under state of firstorder difference, which indicated that the six variables were $I(1)$ sequences and could be used to make co-integrative analysis. 
Table 1.: Unit root test

\begin{tabular}{|l|r|r|r|r|}
\hline \multicolumn{1}{|c|}{ Index } & Test form & ADF test value & $\begin{array}{c}\text { o. } 05 \text { critical } \\
\text { value }\end{array}$ & Unit root or not \\
\hline InGXB & $(\mathrm{C}, \mathrm{N}, 1)$ & -1.74 .09 & -2.9384 & Yes \\
$\Delta \mathrm{InGXB}$ & $(\mathrm{C}, \mathrm{T}, 1)$ & -4.6711 & -2.9511 & No \\
InHFF & $(\mathrm{C}, \mathrm{T}, 1)$ & -2.2770 & $-3.544^{3}$ & Yes \\
$\Delta \mathrm{InHFF}$ & $(\mathrm{C}, \mathrm{T}, 1)$ & -6.2185 & $-3.544^{3}$ & No \\
InJXF & $(\mathrm{C}, \mathrm{T}, 1)$ & -2.8291 & -3.54 .03 & Yes \\
$\Delta \mathrm{InJXF}$ & $(\mathrm{C}, \mathrm{T}, 1)$ & -7.04 .03 & -3.5443 & No \\
InJJF & $(\mathrm{C}, \mathrm{T}, 1)$ & -1.6707 & -3.54 .03 & Yes \\
$\Delta \mathrm{InJJF}$ & $(\mathrm{C}, \mathrm{T}, 1)$ & -6.5592 & -2.94 .84 & No \\
InLDL & $(\mathrm{C}, \mathrm{T}, 1)$ & -1.5117 & -3.54 .03 & Yes \\
$\Delta \mathrm{InLDL}$ & $(\mathrm{C}, \mathrm{T}, 1)$ & -6.7291 & -3.544 .3 & No \\
InLDW & $(\mathrm{C}, \mathrm{T}, 1)$ & -2.3165 & -3.54 .03 & Yes \\
$\Delta \mathrm{InLDW}$ & $(\mathrm{C}, \mathrm{T}, 1)$ & -4.84 .61 & -3.544 .3 & No \\
\hline
\end{tabular}

Source: Author's

Note: $\mathrm{C}, \mathrm{T}, \mathrm{K}$ in test form $(\mathrm{C}, \mathrm{T}, \mathrm{K})$ represented intercept, time trend and the lag period, $\mathrm{N}$ referred to no Gor T.

\subsection{Co-integrative Test}

Common methods of making co-integrative test were Engle-Granger's Two Stage method (abbreviated as EG) and Johnson-Juselius' loglikehood method (abbreviated as JJ). EG was only useful to make co-integrative relationship between two variables, while JJ could make analysis on many variables, therefore, JJ was chose to make co-integrative test. In addition, the optimal lag order of each variable should be detected before implementing co-integrative test. Here, AIC and SC as the judging criterion, and it could be learned that 2 was the optimal order. Later, Eigen value and Max-Eigen statistic were used to assure the number of co-integrative vectors.

Table 2.: JJ co-integrative test

\begin{tabular}{|l|r|r|r|r|r|}
\hline \multicolumn{1}{|c|}{ Eigen value } & $\begin{array}{c}\text { Max-Eigen } \\
\text { Statistic }\end{array}$ & $\begin{array}{c}0.05 \text { Critical } \\
\text { Value }\end{array}$ & Prob. & Ho & Hi \\
\hline 0.9006 & 78.4 .8 & 43.42 & 0.0000 & $\mathrm{r}=0$ & $\mathrm{r}=1$ \\
0.8571 & 66.17 & 37.16 & 0.0000 & $\mathrm{r} \leq 1$ & $\mathrm{r}=2$ \\
0.6425 & 34.99 & 30.82 & 0.0146 & $\mathrm{r} \leq 2$ & $\mathrm{r}=3$ \\
0.4763 & 21.99 & 24.25 & 0.0968 & $\mathrm{r} \leq 3$ & $\mathrm{r}=4$ \\
0.3333 & 13.79 & 17.15 & 0.1446 & $\mathrm{r} \leq 4$ & $\mathrm{r}=5$ \\
0.0014 & 0.05 & 3.84 & 0.8246 & $\mathrm{r} \leq 6$ & $\mathrm{r}=6$ \\
\hline
\end{tabular}

Source: Author's

Under 5 percent significant level, the above variables existed three co-integrative equations for consideration of result of JJ co-integrative test. But, there was only 
one equation demonstrating internal relationship between GXB and the other five variables, therefore, it could be considered that there owned long-term equilibrium relationship between balance degree of supply and demand of the cereal and the above five. Here came to the co-integrative equation:

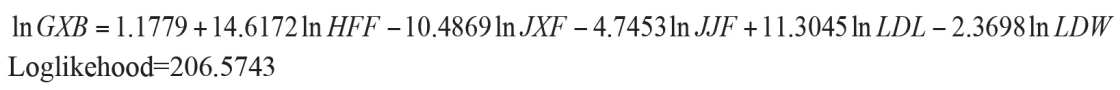

As to the above equation, all five variables passed t test, and it could be considered that the above five cut into co-integrative relationship significantly, which implied that the above five were very important to maintain stability of the system. From the above co-integrative equation, we could learn that JXF, JJF and LDW was positive to achieve cereal's supply and demand's balance, with the coefficient being -10.4869, $-4.745^{3}$ and -2.3698 respectively, which implied acceleration of introducing advanced agricultural equipment, increase of indirect expenditure and increase of agricultural laborer's salary were beneficial to improve supply and demand's balance. The coefficient of JXF achieved the highest positive value showed that extensive developing mode for cereal production should be replaced by the intensive mode, such as using more advanced mechanical equipment. The agricultural laborer's salary for the cereal increased, which would attract more talented laborer with much knowledge and skill to deal with production of the cereal, and this was beneficial for China's smoothing phenomenon of short of supply, which would induce balance of supply and demand of the cereal. As the above defined, the indirect cost implied advanced capital to encourage production of the cereal, therefore, increase of this type of cost would accelerate production of the cereal, and this was coincided with the above econometric result.

Meanwhile, HFF and LDL had negative impact on cereal's supply and demand's balance, and the coefficient reached over 10 respectively. The influence of LDL was negative might be the reason of China's cereal production with excess laborers inducing negative marginal productive utility, therefore, China should drive more laborers out of production of the cereal. The influence of LDL being negative and the influence of LDW being positive were not in conflict, which demonstrated that too much laborer in extensive production of the cereal was not necessary, and at the same time, higher wage would drive more talented laborer to modify extensive production into intensive production. Even though the influence of HFF reached enormous, but as time went on, the use of fertilizer would comparatively drop rapidly for reason of other advanced equipment (such as, the machinery equipment) being used more, and this would induce the influence to be less in the future.

\subsection{Vector Error Correction Model}

According to Granger's opinion, variables with co-integrative relationship could set the vector error correction model (Granger, 1987). The above six variables 
were obedient to $I(1)$ sequences and co-integrative relationship was confirmed, therefore, further analysis could be made on short-term dynamic relationship by implementing the vector error correction model. Let the residual sequence of the above co-integrative equation being $\mathrm{ecm}_{t}$, the following vector error correction model was set.

$$
\begin{aligned}
& \Delta \ln G X B_{i}=c+c_{1} e c m_{t-1}+c_{2 i} \sum_{i}^{k} \Delta \ln G X B_{t-i}+c_{3 i} \sum_{i}^{k} \Delta \ln J X F_{t-i}+c_{4 i} \sum_{i}^{k} \Delta \ln J J F_{t-i} \\
& +c_{5 i} \sum_{i}^{k} \Delta \ln J J F_{t-i}+c_{6 i} \sum_{i}^{k} \Delta \ln L D L_{t-i}++c_{7 i} \sum_{i}^{k} \Delta \ln L D W_{t-i}+\varepsilon_{t}
\end{aligned}
$$

Here, $\mathrm{ecm}_{t-1}$ referred to first-order lag residual of the co-integrative equation.

As to econometric result, the second order was the optimal order, hence, it could be learned that i was 2. Put corresponding data into the vector error correction model, the following estimation was achieved.

$$
\begin{aligned}
\Delta \ln G X B_{i}= & 0.0794-0.0220 e^{c} m_{t-1}-0.2630 \Delta \ln G X B_{t-1}-0.0558 \Delta \ln G X B_{t-2} \\
& +0.6019 \Delta \ln H F F_{t-1}+0.1071 \Delta \ln H F F_{t-2}-0.8976 \Delta \ln J X F_{t-1}+0.5467 \Delta \ln J X F_{t-2} \\
& +1.3072 \Delta \ln J J F_{t-1}+0.6261 \Delta \ln J J F_{t-2}-0.4349 \Delta \ln L D L_{t-1}+0.8120 \Delta \ln L D L_{t-2} \\
& -2.5354 \Delta \ln L D W_{t-1}-2.1498 \Delta \ln L D W_{t-2}
\end{aligned}
$$

According to the above estimating equation, the coefficient of error correction was $2.2 \%$, which implied that correcting deviation between balance degree of the cereal's supply and demand and the long-term value or the equilibrium value was about 2.2 percent each year. GXB with First-order lag and second-order lag would improve balance degree of supply and demand respectively, so did those of LDW. At the same time, HFF with first-order lag and second-order lag would deteriorate balance degree of supply and demand respectively, so did those of JJF. Meanwhile, JXF with first-order lag and LDL with first-order lag was positive to improve balance degree of supply and demand respectively, while those of JXF with second-order lag and LDL with second-order lag was the opposite respectively. Either influence of LDW with first-order lag or that of LDW with second-order lag exceeded 2, which was significantly larger than the other, and demonstrated that increase of agricultural laborer's salary was most useful method to improve balance degree of the cereal's supply and demand. Comparison with the co-integrative equation and the error correction estimation, it could be achieved that HFF would deteriorate and LDW would improve supply and demand's balance, either at short-term or at long-term; JJF would improve supply and demand's balance at short-term, but that was on the contrary at long-term; JXF would improve balance situation at short-term while LDL would deteriorate that at short-term, and the above two variables achieved vague impact at long-term. 


\subsection{Granger Causality Test}

For the same reason of making the vector error correction model, Granger causality test was made for detecting the relationship between GXB and the other five variables. After choosing suitable lag length and being under 10 percent significant level, we could know that HFF, JXF, JJF, LDL and LDW were direct causal reasons of GXB, GXB was direct causal reason of LDL, GXB was not direct causal reason of HFF, JXF, JJF and LDW, which demonstrated that there did not own interactive effect between cereal's supply and demand's balance and the cost factors (including labor cost), but maintain interactive effect between the cereal's supply and demand's balance and input of quantity of the laborer.

Table 3.: Pairwise granger causality test

\begin{tabular}{|l|r|r|}
\hline \multicolumn{1}{|c|}{ Null Hypothesis } & F & P \\
\hline HFF does not Granger Cause GXB & 5.469 & 0.009 \\
JXF does not Granger Cause GXB & 5.465 & 0.009 \\
JJF does not Granger Cause GXB & 4.737 & 0.016 \\
LDL does not Granger Cause GXB & 3.574 & 0.04 .0 \\
LDW does not Granger Cause GXB & 6.047 & 0.006 \\
GXB does not Granger Cause HFF & 0.4 .03 & 0.672 \\
GXB does not Granger Cause JXF & 1.728 & 0.195 \\
GXB does not Granger Cause JJF & 0.999 & 0.380 \\
GXB does not Granger Cause LDL & 3.004 & 0.065 \\
GXB does not Granger Cause LDW & 1.910 & 0.166 \\
\hline
\end{tabular}

Source: Author's

\section{CONCLUSIONS}

The wheat and products, the rice (including the milled equivalent), the maize and products being three main cereals in China, this article analyzed degree of balance of supply and demand of the cereal and carried co-integrative analysis to detect relevant influencing factors by taking data in $1975^{-2011}$. The above three categories occupied about 90 percent of the cereal, and there existed obvious difference on degree of balance of supply and demand as per the three, which demonstrated that self-sufficient ratio of the rice (including the milled equivalent) being the highest, then that of the maize and products and the cereal (excluding beer), and the wheat and products being the least in general. At the same time, China's cereal was in state of serious insufficient or comparative insufficient in general except the rice (including the milled equivalent) before 1997, and then was in state of fully sufficient (except that in 2005), which indicated that hypothesis being "Who will feed China" was not a real problem. On the contrary, China could achieve comparative balanced supply and demand of the cereal. 
The fertilizer expenditure, the machinery cost, the indirect cost, the quantity of labor input and the daily average labor price being independent variables and the cereal's supply and demand's balance being dependent variable, co-integrative model was set to analyze influencing factors. The result showed that the above variables were $I(1)$ sequences and there existed long-term co-integrative relationship between the cereal's supply and demand's balance and the five variables. The vector error correction model demonstrated that correcting coefficient was about 2.2 percent each year, increase of the fertilizer expenditure would deteriorate and increase of the daily average labor price would improve supply and demand's balance, increase of the indirect cost would improve supply and demand's balance at short-term but not at long-term, increase of the machinery cost would improve while increase of the quantity of labor input would deteriorate balance situation at short-term but the above two achieved vague impact at long-term. The Granger causality test showed that the above five variables were direct causes of the cereal's supply and demand's balance, but the cereal's supply and demand's balance was not direct cause for the five variables generally respectively. 


\section{REFERENCES}

Bramall, C., "The Roll of Decollectivisation in China's Agricultural Mirage, 1978-90", Journal of Peasant Studies, 20(2) (2008): 271-295

Brown, L.R., "Who Will Feed China?: Wake-up Call for a Small Planet", W.W. Norton \& Company, U.S.A: New York, 1995 .

Bruins, H.J., Bu, F.X., "Food Security in China and Contingency Planning: the Significance of Grain Reserves", Journal of Contingencies \& Crisis Management, 14, (3) (2006): 114-124

Chen, Y.F., Nie, F.Y., "Analysis of China's Food Supply and Demand Balance and Food Security", Springer Japan, 2016.

Fan, T.L., Stewart B.A., Payne, W.A., Yong, W., Luo, J.J., Gao, Y.F., "Long-term Fertilizer and Water Availability Effects on Cereal Yield and Soil Chemical Properties in Northwest China", Soil Science Society of America Journal, 69 (3) (2005): 842-855

Fan M.S., Lal, R., Cao, J., Qiao, L., Su, Y.S., Jiang, R.F., Zhang, F.S., "Plant-Based Assessment of Inherent Soil Productivity and Contributions to China's Cereal Crop Yield Increase since 1980", PLoS ONE, 8 (9) (2013), doi:10.1371/journal.pone.0074617

Fang, S., "Grain Price Fluctuation Foreshadows an Agricultural Crisis in Mainland China", Advances in Agronomy, 30(1994): 107-109

Granger, C.W.J., "Some Recent Development in a Concept of Causality", Journal of Econometric, 39(1987): $199^{-211}$

Holtkamp, N., Liu, P., McGuire, W., "Regional Patterns of Food Safety in China: What can we learn from media data", China Economic review, 30(2014): 459-4,68

Li, M., Zhang, J., "Distinguishing Chinese Grain Safety from the Angle of Economy Ecologization”, Springer Singapore, 2016.

Liu, R.D., Pieniak, Z., Verbeke, W., "Food-related Hazards in China: Consumers' Perceptions of Risk and Trust in Information Sources", Food Control, 46 (2014): 291-298

Liu, X.M, "International Perspectives on Food Safety and Regulations - a Need for Harmonized Regulations: Perspectives in China", Journal of the Science of Food and Agriculture, 94 (10) (2014): 1928-1931

Pan, G.X., Smith, P., Pan, W.N., "The Role of Soil Organic Matter in Maintaining the Productivity and Yield Stability of Cereals in China", Agriculture Ecosystems \& Environment, 129 (1) (2009): 344-34.8

Shea, E.Y.P., "Understanding China's grain procurement policy from a perspective of optimization", China Economic Review, 21 (4) (2010): 639-649

Wang, H.X., Zhang, M.H., Cai, Y., "Problems, Challenges, and Strategic Options of Grain Security in China", Advances in Agronomy, 103 (2009):101-147

Wang, M., Sun, Y., Shna, L.J., "Grains Quality and Safety Management Situation and Its Countermeasures in China", Journal of Food Agriculture \& Environment, 9 (3 and 4) (2011): 85-88

Wang, Y.B., Wu, P.T., Zhao, X.N. Engel, B.A., "Virtual Water Flows of Grain within China and Its Impact on Water Resource and Grain Security in 2010", Ecological Engineering, 69 (2014): 255-264

Wei, Xing, Zhao Zhang, Peijun Shi, Pin Wang, Yi Chen, Xiao Song, and Fulu Tao. "Is yield increase sufficient to achieve food security in China?." PloS one 10, no. 2 (2015): eo116430 
Xiong, W., D. Conway, Y. L. Xu, J. Jiang, Y. Li, S. Calsamiglia-Mendlewicz, E. D. Lin, and J. Hui. "Future cereal production in China: Modelling the interaction of climate change, water availability and socioeconomic scenarios. The Impacts of Climate Change on Chinese Agriculture-Phase II Final Report." (2008)

Xu, Ningshan, Yuduo Lu, and Haiteng Wang. "Enlightenment on India and Japan Grain Safety Policy for China-A Case Study from a Macro Perspective." In Proceedings of 2015 2nd International Conference on Industrial Economics System and Industrial Security Engineering, Springer Singapore, (2016): 237-244

Yeh, G., "Mainland China Grain Crises", Issues \& Studies, 25 (12) (1989): 68-82

Zhang, T.Y., Yao, Y., "Impacts of Climate Change and Inter-annual Variability on Cereal Crops in China from 1980 to 2008", Journal of the Science of Food and Agriculture, 92(8) (2012): 1643-1652

Zhang. Y., "China's Grain Safety Considerations under the Perspective of Cultivated Land", South China Rural Area, 29(4) (2013): 47-53 (In Chinese)

Zhou, Zhangyue, and Xian Xin. "China's feedgrain demand in global perspective." In Globalization and Chinese Agriculture, China Agriculture Press, (2006): 112-128

Zhu, Huying, Peter Jackson, and Wentao Wang. "Consumer anxieties about food grain safety in China." Food Control 73 (2017): 1256-1264 